University of New Hampshire

University of New Hampshire Scholars' Repository

Master's Theses and Capstones

Student Scholarship

Winter 2020

\title{
Experimental Investigation and Plasticity Modeling of SS316L Microtubes Under Varying Deformation Paths
}

Elizabeth Marie Mamros

University of New Hampshire, Durham

Follow this and additional works at: https://scholars.unh.edu/thesis

\section{Recommended Citation}

Mamros, Elizabeth Marie, "Experimental Investigation and Plasticity Modeling of SS316L Microtubes Under Varying Deformation Paths" (2020). Master's Theses and Capstones. 1431.

https://scholars.unh.edu/thesis/1431

This Thesis is brought to you for free and open access by the Student Scholarship at University of New Hampshire Scholars' Repository. It has been accepted for inclusion in Master's Theses and Capstones by an authorized administrator of University of New Hampshire Scholars' Repository. For more information, please contact Scholarly.Communication@unh.edu. 


\title{
EXPERIMENTAL INVESTIGATION AND PLASTICITY MODELING OF SS316L MICROTUBES UNDER VARYING DEFORMATION PATHS
}

\author{
BY \\ ELIZABETH M. MAMROS \\ Erie, The Behrend College, 2018 \\ THESIS \\ Submitted to the University of New Hampshire \\ in Partial Fulfillment of \\ the Requirements for the Degree of \\ Master of Science \\ in \\ Mechanical Engineering
}

Baccalaureate of Science Mechanical Engineering, The Pennsylvania State University -

December, 2020 
This thesis has been examined and approved in partial fulfillment of the requirements for the degree of Master of Science in Mechanical Engineering by:

Thesis Director, Brad Kinsey, Professor of Mechanical Engineering and Materials Science Thesis Director, Jinjin Ha, Assistant Professor of Mechanical Engineering

Igor Tsukrov, Professor of Mechanical Engineering and Materials Science

On November 30, 2020

Original approval signatures are on file with the University of New Hampshire Graduate School. 


\section{ACKNOWLEDGEMENTS}

I would like to extend my thanks and appreciation to all who helped me to complete this degree.

I would like to express my gratitude to my research advisors, Dr. Brad Kinsey and Dr. Jinjin Ha, for their continued guidance and support.

I would also like to extend special thanks to Dr. Igor Tsukrov for serving as a member of my thesis committee.

Thank you to the U.S. National Science Foundation for providing funding for the New Hampshire (NH) BioMade Project through the Established Program to Stimulate Competitive Research (EPSCoR) Research Infrastructure Improvement Award \#1757371.

Finally, I wish to thank my family, friends, and colleagues who have supported me throughout my graduate school journey. 


\section{TABLE OF CONTENTS}

ACKNOWLEDGEMENTS iii

LIST OF TABLES Vi vi v v v v

LIST OF FIGURES vii

ABSTRACT ix

JOURNAL PUBLICATION DETAILS - xi

INTRODUCTION 1

1 EXPERIMENTS $\quad 3$

1.1 Experimental Setup and Methods . . . . . . . . . . . . . . 3

1.1.1 Microtube Inflation/Tension Machine . . . . . . . . . . . . . . . . 4

1.1.2 Digital Image Correlation and Thermal Imaging . . . . . . . . . . . 6

1.1 .3 Material ....................... 6

1.1.4 Inflation/Tension Experiments . . . . . . . . . . . . . . . . 8

1.2 Experimental Results . . . . . . . . . . . . . . . . . . . . . 9

1.3 Discussion . . . . . . . . . . . . . . . . . . . . . . 11

2 PLASTICITY MODELING $\quad 14$

2.1 Anisotropic Yield Criterion . . . . . . . . . . . . . . . . . 14

2.2 Strain Hardening Law . . . . . . . . . . . . . . . . . . . . . . . . 16 
2.3 Model Implementation . . . . . . . . . . . . . . . . . . . . . 17

2.4 Model Validation . . . . . . . . . . . . . . . . . 18

2.5 Discussion . . . . . . . . . . . . . . . . . . . . . . . 20

3 CONCLUSIONS $\quad 22$

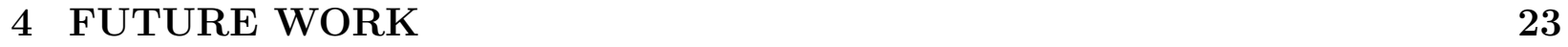

$\begin{array}{ll}\text { LIST OF REFERENCES } & 27\end{array}$

$\begin{array}{ll}\text { A SUPPLEMENTAL FIGURES } & 28\end{array}$

B MATLAB CODE $\quad 30$ 


\section{LIST OF TABLES}

1.1 Chemical composition of SS316L in mass percent \% [21] . . . . . . . . 7

2.1 Anisotropic material parameters for Hill 48 yield criterion . . . . . . . . . . . 15

2.2 Strain hardening parameters of Hockett-Sherby law . . . . . . . . . . . 17 


\section{LIST OF FIGURES}

1.1 Microtube inflation/tension testing machine, a) entire system and b) close-up of tensile stage with microtube assembly inserted . . . . . . . . . . . 3

1.2 Schematic of microtube specimen assembly inside of grip (modified from [13]) 5

1.3 Experimental 3D DIC true a) axial and b) hoop strains and c) thermal image from a $\sigma_{x}: \sigma_{\theta}=5: 4$ proportional loading test . . . . . . . . . . . 7

1.4 Optical microscope image of as-received SS316L microtube grains in the hoopthickness $(\theta-t)$ plane . . . . . . . . . . . . . . . . 8

1.5 True stress-strain curves for pure hoop and pure axial loading . . . . . . . . 9

1.6 Experimental true a) stress and b) strain for SS316L deformation paths . . . 10

1.7 Variation in strain paths depending on axial location considered due to grain size effects for a hoop to axial corner path test . . . . . . . . . . . . 12

1.8 Repeatability of axial to hoop experiment with $\sigma_{x}=505 \mathrm{MPa}$ transition true

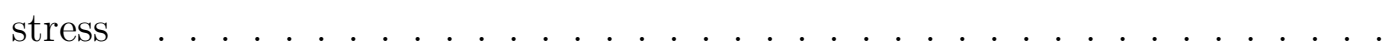

2.1 Yield loci of Hill 48 anisotropic yield criterion calibrated based on strain ratios and von Mises isotropic yield criterion . . . . . . . . . . . 16

2.2 Hockett-Sherby law fitted to SS16L uniaxial experimental data . . . . . . . 17

2.3 Flow diagram of model to predict strain paths from stress paths . . . . . . 18

2.4 Comparison of von Mises and Hill 48 strain path predictions with experimental

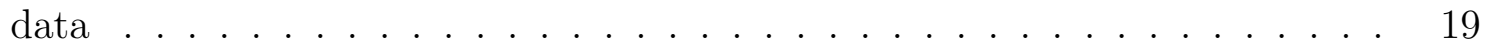

2.5 Comparison of predicted, i.e., model, and experimental true a) stress and b) strain for SS316L deformation paths . . . . . . . . . . . . 20 
A.1 Engineering a) stress and b) strain paths from corner (solid) and proportional (dashed) loading path experiments . . . . . . . . . . . . . . 28

A.2 Experimental 3D DIC true a) axial and b) hoop strains from a hoop to axial corner loading test just prior to failure $\ldots \ldots \ldots \ldots \ldots \ldots$ 


\begin{abstract}
EXPERIMENTAL INVESTIGATION AND PLASTICITY MODELING OF SS316L MICROTUBES UNDER VARYING DEFORMATION PATHS

by

Elizabeth M. Mamros

University of New Hampshire, December, 2020
\end{abstract}

Results for SS316L microtube experiments under combined inflation and axial loading for single and multi-loading segment deformation paths are presented along with a plasticity model to predict the associated stress and strain paths. The microtube inflation/tension machine, utilized for these experiments, creates biaxial stress states by applying axial tension or compression and internal pressure simultaneously. Two types of loading paths are considered in this paper, proportional (where a single loading path with a given axial:hoop stress ratio is followed) and corner (where an initial pure loading segment, i.e., axial or hoop, is followed by a secondary loading segment in the transverse direction, i.e., either hoop or axial, respectively). The experiments are designed to produce the same final strain state under different deformation paths, resulting in different final stress states. This difference in stress state can affect the material properties of the final part, which can be varied for the intended application, e.g., biomedical hardware, while maintaining the desired geometry. The experiments are replicated in a reasonable way by a material model that combines the Hill 1948 anisotropic yield function and the Hockett-Sherby hardening law. Discussion of the 
grain size effects during microforming impacting the ability to achieve consistent deformation path results is included. 


\section{JOURNAL PUBLICATION DETAILS}

This thesis is based on the following publication in the "Advances in Micro and NanoManufacturing" special issue of the American Society of Mechanical Engineer's Journal of Micro and Nano- Manufacturing published in December 2020:

Mamros, E. M., Ha, J., Korkolis, Y. P., and Kinsey, B. L., 2020, "Experimental Investigation and Plasticity Modeling of SS316L Microtubes under Varying Deformation Paths," JMNM, $8(4)$.

As the first and only student author, I performed nearly all of the work for this publication. I conducted all experiments in the laboratory, completed all data post-processing, coded and executed the plasticity model to generate data, created all figures, and wrote the initial draft of the manuscript text. My advisors, Dr. Ha and Dr. Kinsey along with our collaborator from the Ohio State University, Dr. Korkolis, contributed to the work by editing the manuscript and providing their expert perspectives on the research. 


\section{INTRODUCTION}

Over the past two decades, with the growing trend of miniaturization, research focused on micromanufacturing has been building momentum to establish a link between macroscale manufacturing and nanomanufacturing and to create state-of-the-art microscale components. The latest findings include applications-driven processes such as micro-machining, microEDM, micro-electrochemical machining, and micro-powder injection molding [1]. In terms of microforming, several processes have been scaled-down and studied, such as single point incremental forming [2] and microtube bending [3]. As at the macroscale, microforming is a high production rate process with exceptional material utilization. In order to achieve high precision and product quality, a fundamental understanding of the processes in addition to accurate prediction models and simulations are needed.

With the decrease in length scale, several new challenges arrive for manufacturers. Assumptions neglecting certain effects in macroscale manufacturing are no longer valid. Previous studies have shown that material behavior varies significantly at smaller length scales [4-6]. In forming, grain size effects occur when a part feature contains i 10 grains through the cross-section, which implies that empirical and analytical knowledge derived from conventional processes is not necessarily applicable at the microscale [7]. Grain size effects can influence the deformation behavior and resulting defects, e.g., springback [3], surface finish [8], and eccentricity of microtubes.

Other factors that may contribute to the difficulty of rescaling macroscale manufacturing processes to create smaller components include process-material interactions, morphology, mechanical compatibility, equipment resolution, and heat transfer [9]. In addition, stress 
superposition $[10,11]$, which is an emerging area in forming processes where applied stress components are intentionally superimposed during the deformation, has the ability to improve the final part properties, e.g., formability, strength, and geometry. Optimizing and controlling forming parameters according to the intended part application is desired, but methods to accomplish these goals remain to be determined even at the macroscale.

One example of stress superposition is microtubes subjected to multiple biaxial loading segments, i.e., combined axial tension and inflation [12-14]. In these studies, two types of paths were investigated for SS304L: proportional (where a single stress ratio of axial to hoop stress is held constant) and corner (where a pure axial or pure hoop loading segment is executed and then followed by a biaxial stress segment as loading is increased in the transverse direction). A model capable of predicting these deformation paths based on desired final stress and strain states, which will directly affect the material properties, is required to eliminate trial and error approaches.

In this thesis, microtube experimental results and plasticity modeling are presented for single and multi-loading segment deformation paths reaching the same final strain state, but different final stress states. This variability can influence the properties, e.g., strength, heterogeneity in microstructure, and phase fractions, of materials susceptible to plasticityinduced phase transformations. This includes the material used in this study, SS316L, which transforms austenite into martensite with deformation. Plasticity modeling is also presented and shown to reasonably predict the experimental results provided that the anisotropy of the material is captured in the analyses. Therefore, this model can be utilized to optimize the stress paths during forming, which is important for enhancing martensitic transformation, while achieving the same final strain state. 


\section{CHAPTER 1 \\ EXPERIMENTS}

\subsection{Experimental Setup and Methods}

The experimental methods for this research include the machine used, the unique measurement systems incorporated into the process, and the material investigated. Biocompatible materials are of interest due to the potential applications of this work in the healthcare industry. Previous studies were completed using SS304L microtubes [12-14], but this current investigation utilizes a different low-carbon stainless steel, SS316L, due to enhanced biocompatibility. Similar tube failure experiments were also performed on aluminum 6260 and 6061 [15-18], although this is not considered to be a biocompatible material, and the research was conducted on the macroscale.
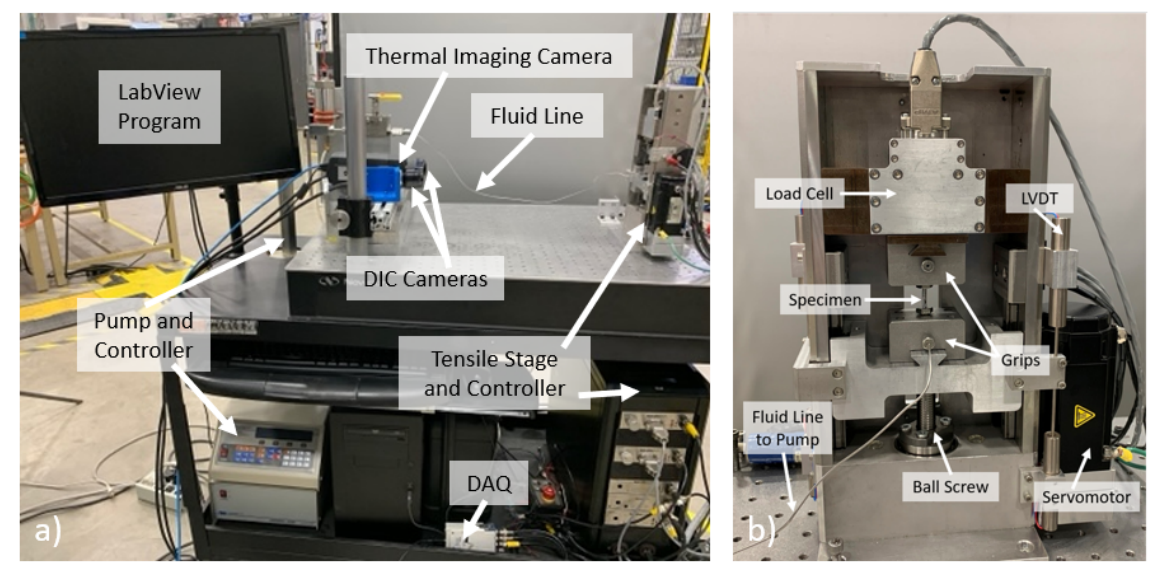

Figure 1.1: Microtube inflation/tension testing machine, a) entire system and b) close-up of tensile stage with microtube assembly inserted 


\subsubsection{Microtube Inflation/Tension Machine}

The experiments were conducted on the custom microtube inflation/tension machine shown in Fig. 1.1 at UNH [12]. This testing machine consists of two major components, a microscale ball screw-driven, tensile stage from Psylotech and a Teledyne ISCO hydraulic pump, which are coupled via a leader-follower relationship in LabVIEW. That is, the axial force follows the internal pressure based on the desired ratio of the loading. The load cell capacity is 2000 $\mathrm{N}$ with a resolution of $1 \mathrm{mN}$, and the maximum displacement is $50 \mathrm{~mm}$ with a linear variable displacement transducer (LVDT) resolution of $25 \mathrm{~nm}$. The pump can reach a maximum flow rate of $25 \mathrm{ml} / \mathrm{min}$ and a maximum pressure of 1380 bar (20 ksi) with resolutions of $3 \%$ of set point and $138 \mathrm{kPa}(20 \mathrm{psi})$, respectively.

The 316L microtube specimens used in the experiments were cut from stock tubing, using a Dremel tool, into lengths varying from 45 to $60 \mathrm{~mm}$ (1.77 to $2.36 \mathrm{in}$ ), dependent upon the loading path of the given test. The shorter lengths are necessary to prevent buckling during inflation, where an axial compressive force is applied to maintain a pure hoop loading condition. To prevent the microtube from crimping while tightening the grips, a hollow, metallic insert $12 \mathrm{~mm}$ (0.47 in) in length was placed in each end creating an 11 to $30 \mathrm{~mm}$ (0.43 to 1.18 in) gage section. Next, the microtube was inserted into customized glands machined on a lathe out of grade 8 high strength steel to have a through hole and tapered opening at the bottom of the threaded end (see Fig. 1.2). Then, 4 conical sleeves (HiP Company) were placed (2 on each end of the specimen) opposite to one another as shown in Fig. 1.2. Lastly, this assembly was inserted into custom, 3D printed metallic grips, shown physically in Fig.1.1b and schematically in Fig. 1.2, and tightened. As the custom gland was tightened, the conical sleeves deformed around the microtube securing the specimen and preventing slippage and leakage. Two sleeves per end were found necessary, to be able to apply the axial tensile forces needed in these experiments without the tube slipping out of the assembly of Fig. 1.2. The stainless steel fluid inlet line was then attached to the bottom grip, and after purging any air from the system, a plug was inserted into the top 
grip creating a closed system. This specimen preparation procedure follows the methodology used by Ripley and Korkolis [12].

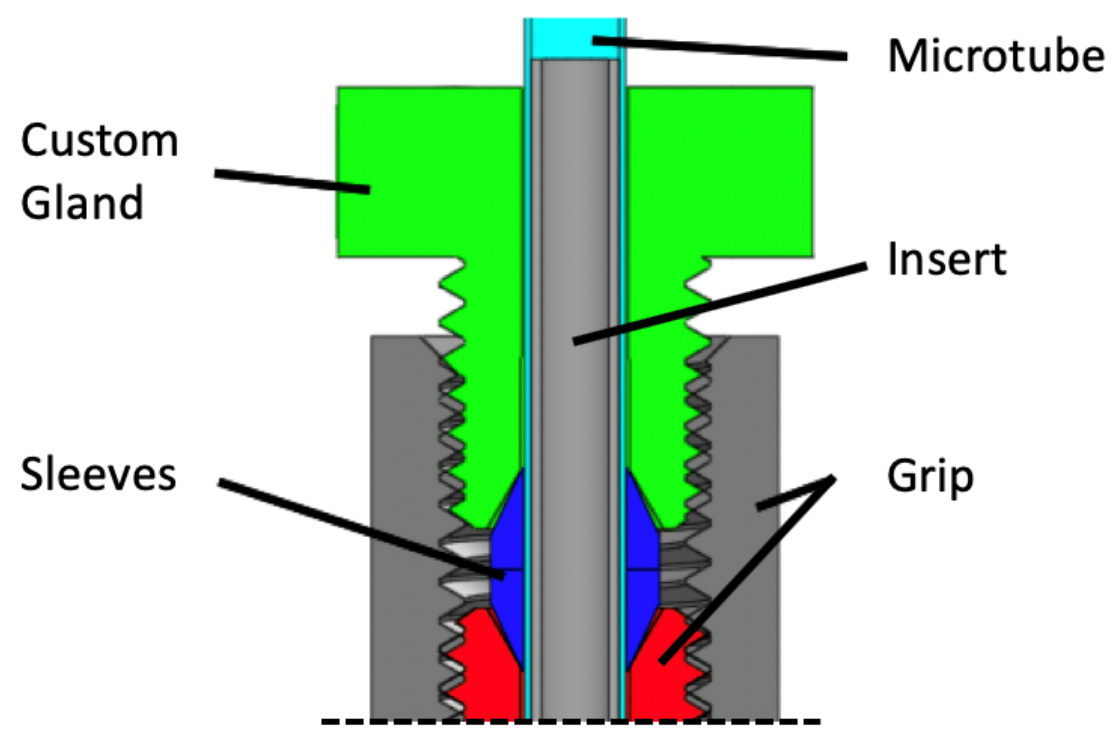

Figure 1.2: Schematic of microtube specimen assembly inside of grip (modified from [13])

The microtube inflation/tension machine operates from a customized LabVIEW program. As mentioned previously, this program maintains a user-specified engineering stress-ratio (i.e., axial:hoop or $\sigma_{x}: \sigma_{\theta}$ ) via a leader-follower relationship. The tubes were inflated under volume control. The pressure sensor, acting as the leader in the system, records a measurement and sends this data to the program. The follower component is the tensile stage, which then receives a signal from the program to apply a force in reaction to the pressure reading, thus maintaining the specified stress ratio. This loading scheme was selected to allow the tubes to continue to deform after the anticipated maximum in the internal pressure (and follower axial force) is attained. In this way, the tubes were taken to failure. The program also features an option to hold the axial stress at a constant value while the pump is increasing the pressure. This allowed for the execution of corner paths, i.e., axial to hoop or hoop to axial (where an initial pure hoop or axial loading segment is followed by a loading segment in the transverse direction). 


\subsubsection{Digital Image Correlation and Thermal Imaging}

Three dimensional Digital Image Correlation (DIC) was utilized to measure the strain field in-situ. Two FLIR 8.9 megapixel cameras were incorporated into the experimental setup (shown in Fig. 1.1a) with $50 \mathrm{~mm}$ Schneider Xenoplan compact lenses. Specimens were spray-painted to have a white background with a black speckle pattern. As deformationinduced heating is known to occur when deforming stainless steels [19-20], a FLIR SC-645 infrared camera (temperature range of $-20^{\circ} \mathrm{C}$ to $650^{\circ} \mathrm{C}$ with a resolution of $0.05^{\circ} \mathrm{C}$ ) was also incorporated into the experimental setup (shown in Fig. 1.1a) to obtain in-situ temperature measurements. A surface emissivity value of 0.98 was used for the thermal imaging based on calibrations with a thermocouple.

All three cameras were coupled using VIC Snap (Correlated Solutions, Inc.) to capture synchronously at $2 \mathrm{~Hz}$. Post-processing of the DIC images was completed in VIC-3D (Correlated Solutions, Inc). The area of interest included the entire gauge length with two virtual extensometers, which calculate the engineering strain based on the displacement of the virtual extensometer end locations, placed in the center along the axial and transverse, i.e., hoop, directions, to extract strain measurements. The DIC parameters include a subset size of 27 , a step size of 9 , and a filter size of 5 pixels to analyze the strain data. See Fig. 1.3 for example strain and thermal fields from the DIC software a few frames prior to failure, showing the localization of strain in a $\sigma_{x}: \sigma_{\theta}=5: 4$ proportional loading test. Note that deformation induced heating is not significant in these experiments, i.e., only $\Delta T \approx+10^{\circ} \mathrm{C}$ compared to the initial temperature, due in part to heat transfer through the inflation fluid in the experiments. Therefore, further temperature results are not presented here. The strain rate for all experiments was approximately $10^{-3}-10^{-5} \mathrm{~s}^{-1}$.

\subsubsection{Material}

Seamless, fully annealed SS316L microtubes with an outer diameter of $2.38 \mathrm{~mm}$ (0.094 in) and a wall thickness of $150 \mu \mathrm{m}$ (0.006 in) were purchased from MicroGroup, part of TE 

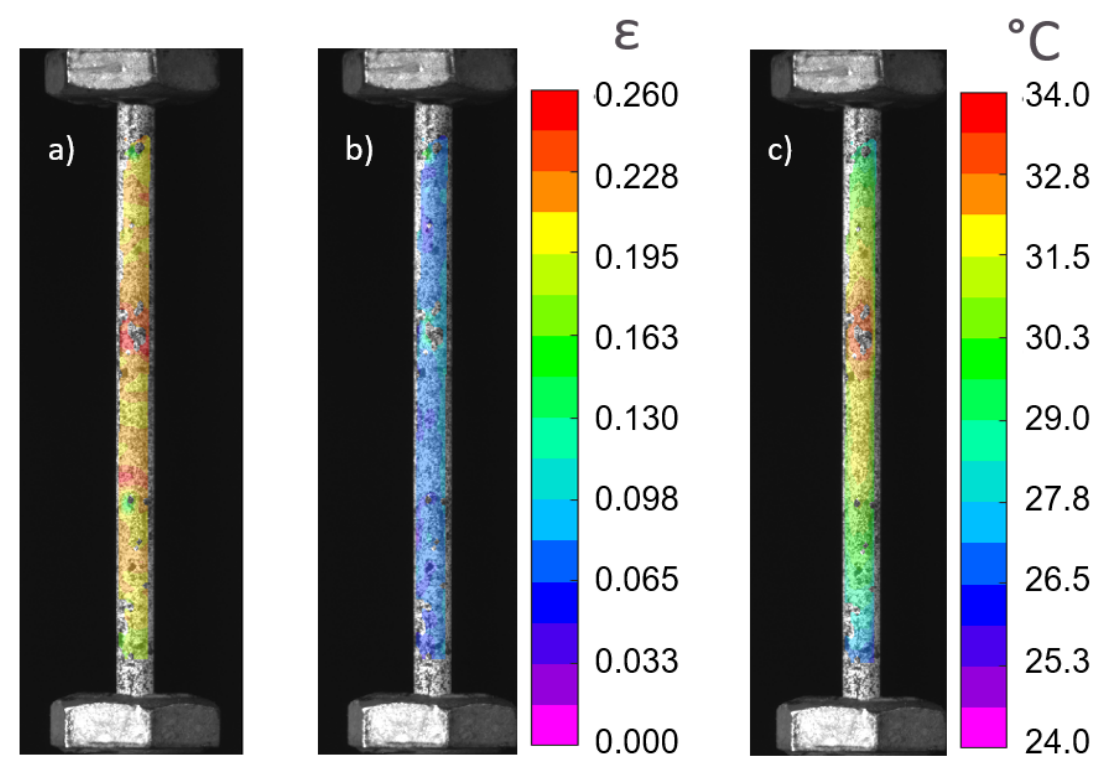

Figure 1.3: Experimental 3D DIC true a) axial and b) hoop strains and c) thermal image from a $\sigma_{x}: \sigma_{\theta}=5: 4$ proportional loading test

Connectivity [21]. Table 1.1 shows the chemical properties reported by the manufacturer. The microstructure of an annealed sample of the material is shown in Fig. 1.4. The optical microscope image was taken from the hoop-thickness $(\theta-t)$ plane after etching the sample in a $10 \mathrm{~mL}$ nitric acid $\left(\mathrm{HNO}_{3}\right), 20 \mathrm{~mL}$ hydrochloric acid $(\mathrm{HCl})$, and $30 \mathrm{~mL}$ water solution. There are approximately 6-8 grains through the thickness in this material, which will directly affect the mechanical behavior due to size effects (i.e., $<\sim 10$ grains through the thickness during microforming) $[3,7]$.

\begin{tabular}{|c|c|c|c|c|c|c|c|c|c|}
\hline $\mathrm{C}$ & $\mathrm{Mn}$ & $\mathrm{P}$ & $\mathrm{S}$ & $\mathrm{Si}$ & $\mathrm{N}$ & $\mathrm{Ni}$ & $\mathrm{Cr}$ & Mo & $\mathrm{Fe}$ \\
\hline 0.020 & 1.640 & 0.031 & 0.010 & 0.380 & 0.043 & 13.100 & 17.350 & 2.640 & Bal. \\
\hline
\end{tabular}

Table 1.1: Chemical composition of SS316L in mass percent \% [21]

For material characterization purposes, pure axial tension and pure hoop experiments were conducted. The resulting true stress-strain curves are shown in Fig. 1.5. Explicitly, the "Pure Axial" tension curve is true axial stress versus true plastic axial strain, and the "Pure Hoop" curve is true hoop stress versus true plastic hoop strain, respectively. As is evident, the material is softer in the pure hoop direction compared to axial tension, and 


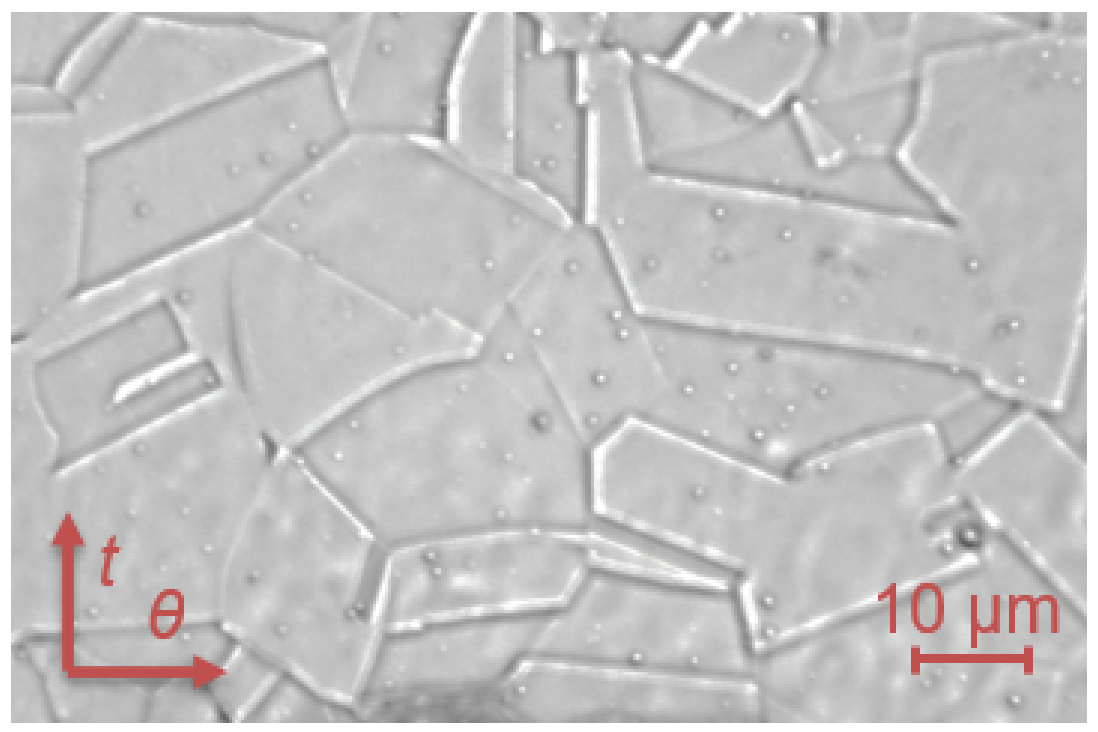

Figure 1.4: Optical microscope image of as-received SS316L microtube grains in the hoopthickness $(\theta-t)$ plane

the relative flow stress ratio changes from 0.86 to 0.80 as the plastic work increases from 0.5 to $150 \mathrm{MJ} / \mathrm{m}^{3}$. This indicates that plastic anisotropy in the flow stress is observable in this material, and furthermore, it evolves as the plastic deformation increases. In addition to the anisotropy in flow stress, the strain anisotropy was characterized by the strain ratio for pure axial tension and pure hoop inflation experiments. The strain ratio was assessed in a similar way to Lankford coefficients, i.e., r-values, for uniaxial tension of sheet materials, which are plastic strain ratios in the transverse to the loading and thickness directions. For the microtube specimens, the ratios for pure axial $\left(r_{x}\right)$ and pure hoop $\left(r_{\theta}\right)$ experiments were calculated by the hoop-to-thickness and axial-to-thickness plastic strains, respectively. The values are $r_{x}=0.908$ and $r_{\theta}=0.820$ and were used to calibrate material parameters in the plasticity modeling.

\subsubsection{Inflation/Tension Experiments}

Two types of loading paths are considered in this paper, proportional (where a single loading path with a given axial:hoop stress ratio is followed) and corner (where an initial pure axial 


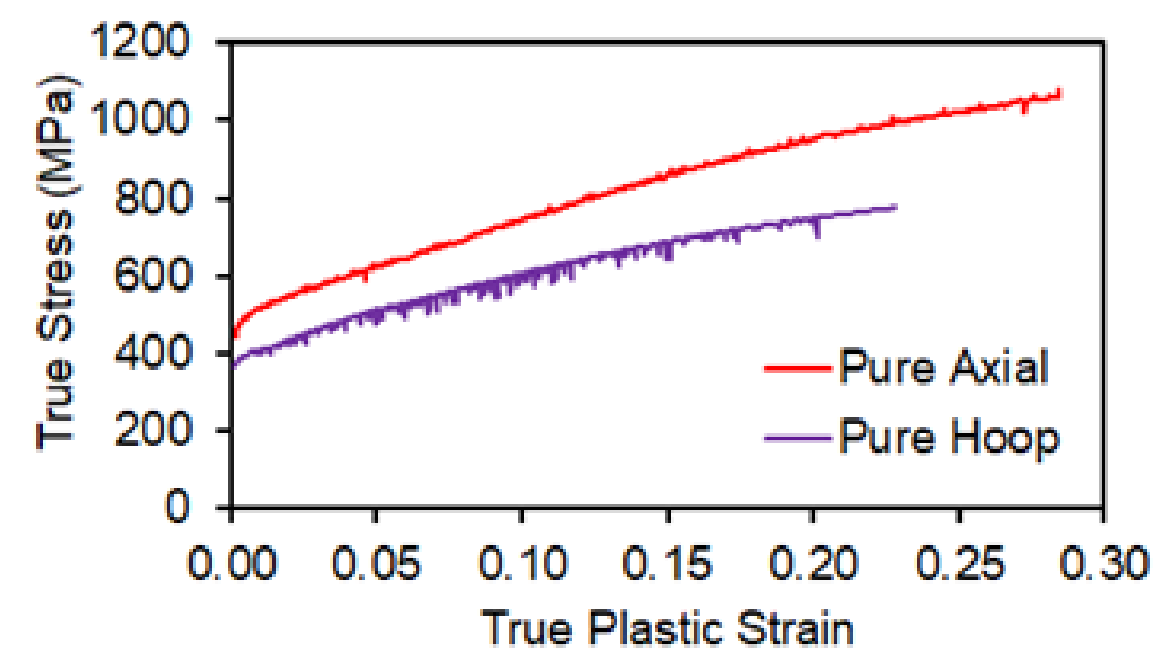

Figure 1.5: True stress-strain curves for pure hoop and pure axial loading

loading segment is followed by a secondary loading segment in the hoop direction). Note that the corner engineering stress value is prescribed during these tests, but for consistency purposes with the model, all results will be presented in terms of true stresses. These experiments demonstrate that significantly different final stress states are required to achieve the same final strain state when the deformation path is altered. As mentioned, this difference in stress state may affect the microstructure, i.e., transformation kinetics of martensite, in this material and alter the final properties. An explanation of concerns related to microforming grain size effects for the alternative loading case, i.e., an initial pure hoop loading segment followed by a secondary axial loading segment, and thus why experimental data is not presented for this loading case, is provided in the Discussion section.

\subsection{Experimental Results}

To demonstrate that varying final stress states are required to achieve the same final strain state and to validate the plasticity model, experimental stress and strain data were collected for various prescribed single loading segment paths with constant stress ratios, i.e., proportional paths, as well as corner paths, e.g., axial to hoop loading, until failure. Note that for corner paths, the second loading segment has a varying stress ratio as the initial loading 
segment's stress value at the path transition is held constant while loading in the other direction is increased. Experiments were conducted for the following proportional paths $\sigma_{x}: \sigma_{\theta}$ $=1: 1,5: 4$, and 1:0 (pure axial). Additionally, three axial to hoop paths and one hoop to axial path (denoted by the true axial or hoop stress value, respectively, at the transition between loading segments in figures) were investigated. The corresponding true stress paths and induced true strain paths are shown in Fig. 1.6a and 1.6b, respectively. The loading paths shown are truncated to the desired final strain state value in most of the figures. The dominant stress dictates the failure mode of the microtube, e.g., if axial stress or hoop stress is greater, the microtube will fail circumferentially or axially respectively [14]. See Fig. A.1 for engineering stress and strain paths including additional experiments.
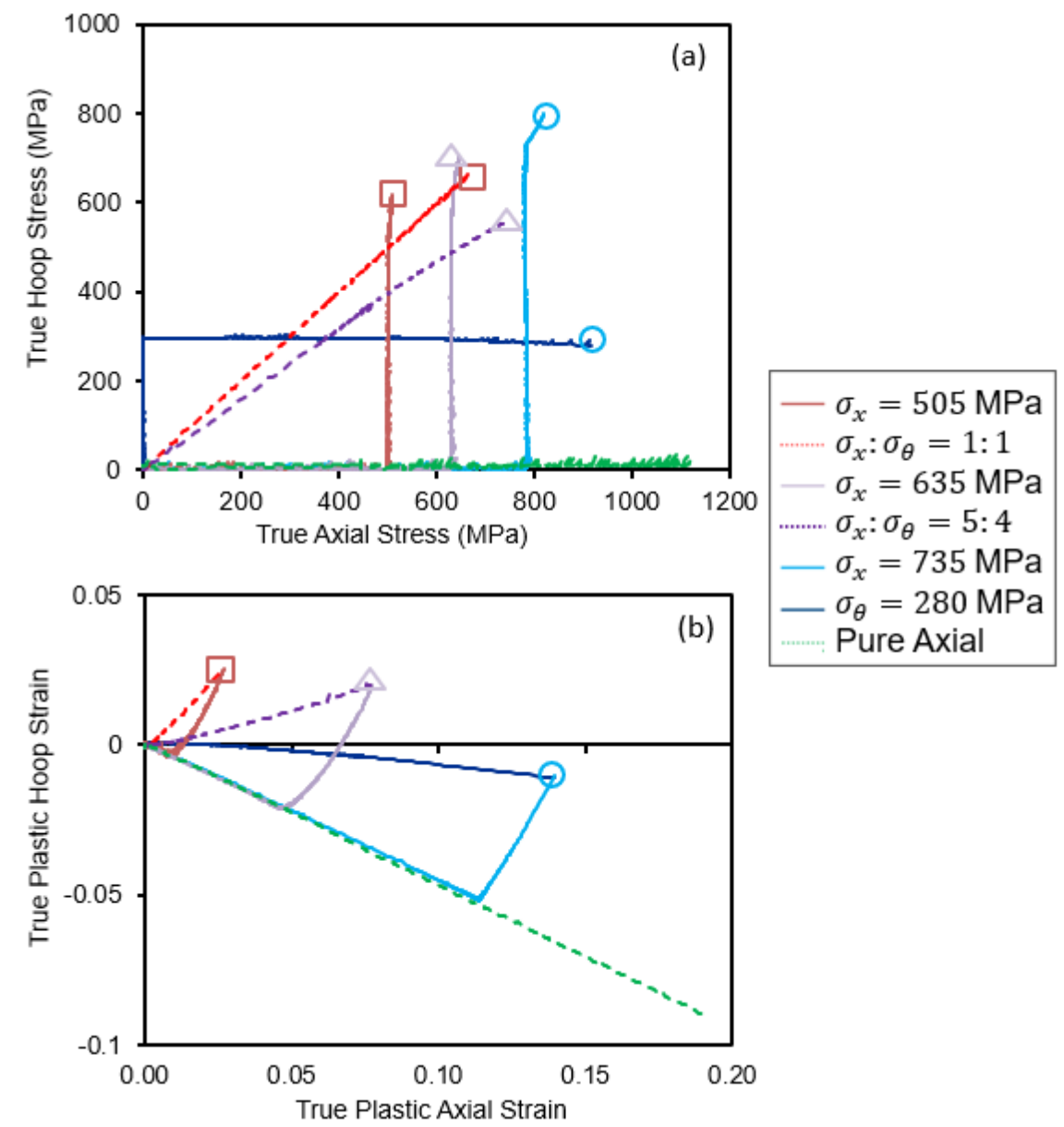

Figure 1.6: Experimental true a) stress and b) strain for SS316L deformation paths 
As is evident in Fig. 1.6, the final stress state is significantly different, despite achieving the same final strain state, for the various deformation paths. This difference increases as the plastic deformation increases. That is, the final stress states for the $\left(\epsilon_{x}, \epsilon_{\theta}\right)=(0.03,0.03)$ final strain state are relatively close (red square markers) compared to the $\left(\epsilon_{x}, \epsilon_{\theta}\right)=(0.14,-0.01)$ final strain state (light blue circle markers), where the specimens have undergone significantly more deformation. Achieving larger strain values will increase the austenite to martensite phase transformations of interest for this material, which will also be affected by the deformation path followed. The phase transformation results will be studied in future research. Note that the pronounced non-vertical change in slope towards the end of the $\sigma_{x}=785 \mathrm{MPa}$ transition true stress case (i.e., light blue path in Fig. 1.6b) is due to strain localization.

\subsection{Discussion}

The corner loading paths investigated were all axial to hoop except for one hoop to axial path that was not loaded beyond the elastic limit of the material, which is $\sigma_{\theta}^{y}=370 \mathrm{MPa}$ for a pure hoop loading. Additional hoop to axial paths are not presented in this research due to significant specimen to specimen variability and grain size effects present during microforming when $<\sim 10$ grains exist through the deformation direction. With only 6-8 grains through the thickness, variability occurred during initial pure hoop loading segments depending on the orientation of grains through the thickness in a given area of the microtube. Figure 1.7 shows how the strain path varied depending on the axial location investigated during a single test to a corner engineering hoop stress of $550 \mathrm{MPa}$. Note that all transverse virtual extensometers shown were plotted against a single axial virtual extensometer to allow for comparison based on the axial placement. The hoop strain values from the different transverse virtual extensometers exhibited deviations of approximately $\pm 13-20 \%$ from the average hoop strain values for the portion of the strain path corresponding to the axial loading segment. Such variability was exacerbated when data from multiple specimens was considered. Often, physical differences due to grain size effect are visibly observed during 
microforming, e.g., during springback [7]. Due to the small deformation induced, this is not the case during these microtube experiments. However, these grain size effects exist and require DIC analyses for observation. See Fig. A.2 for true axial and hoop strain contour images from DIC analyses of the experiment in Fig. 1.7.
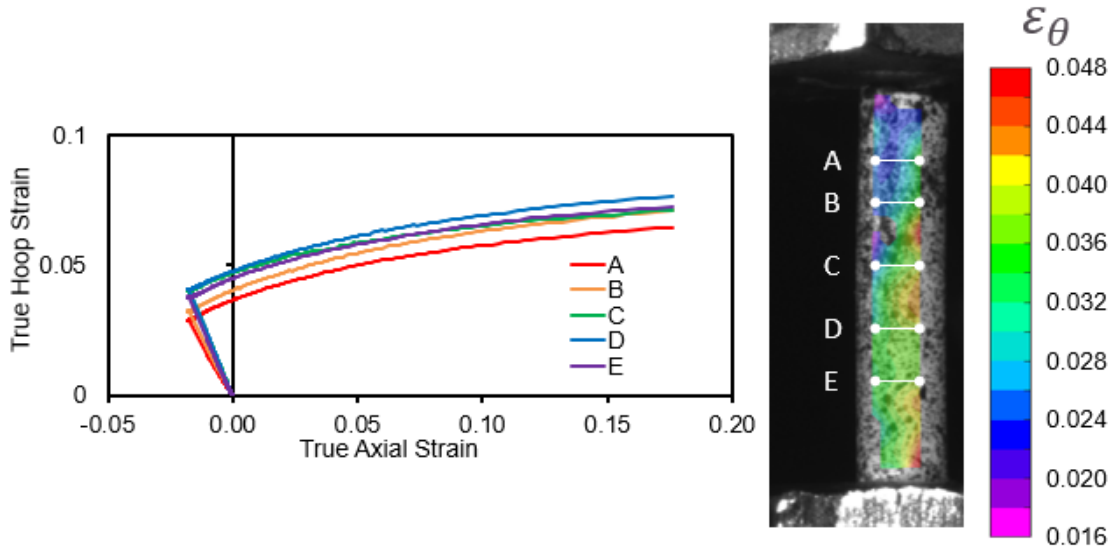

Figure 1.7: Variation in strain paths depending on axial location considered due to grain size effects for a hoop to axial corner path test

In contrast to an experiment with an initial pure hoop path as in Fig. 1.7, with some application of axial tensile loading, whether following a proportional path or an axial to hoop corner path, the variability in strain path curves is not present. When the force is applied in the axial direction, there are several grains through the axial length preventing grain size effects during this axial loading. Even during an axial to hoop corner path, simply applying some axial force improves the repeatability of the tests (see Fig. 1.8 despite loading in the hoop direction during the second segment. Again, this is a clear indication that grain size effects exist during these microtube forming experiments. Note in Figure 1.8 that the true strain paths are shown to failure, but the red square indicates the approximate truncation location for figures where the same final strain state is presented. 


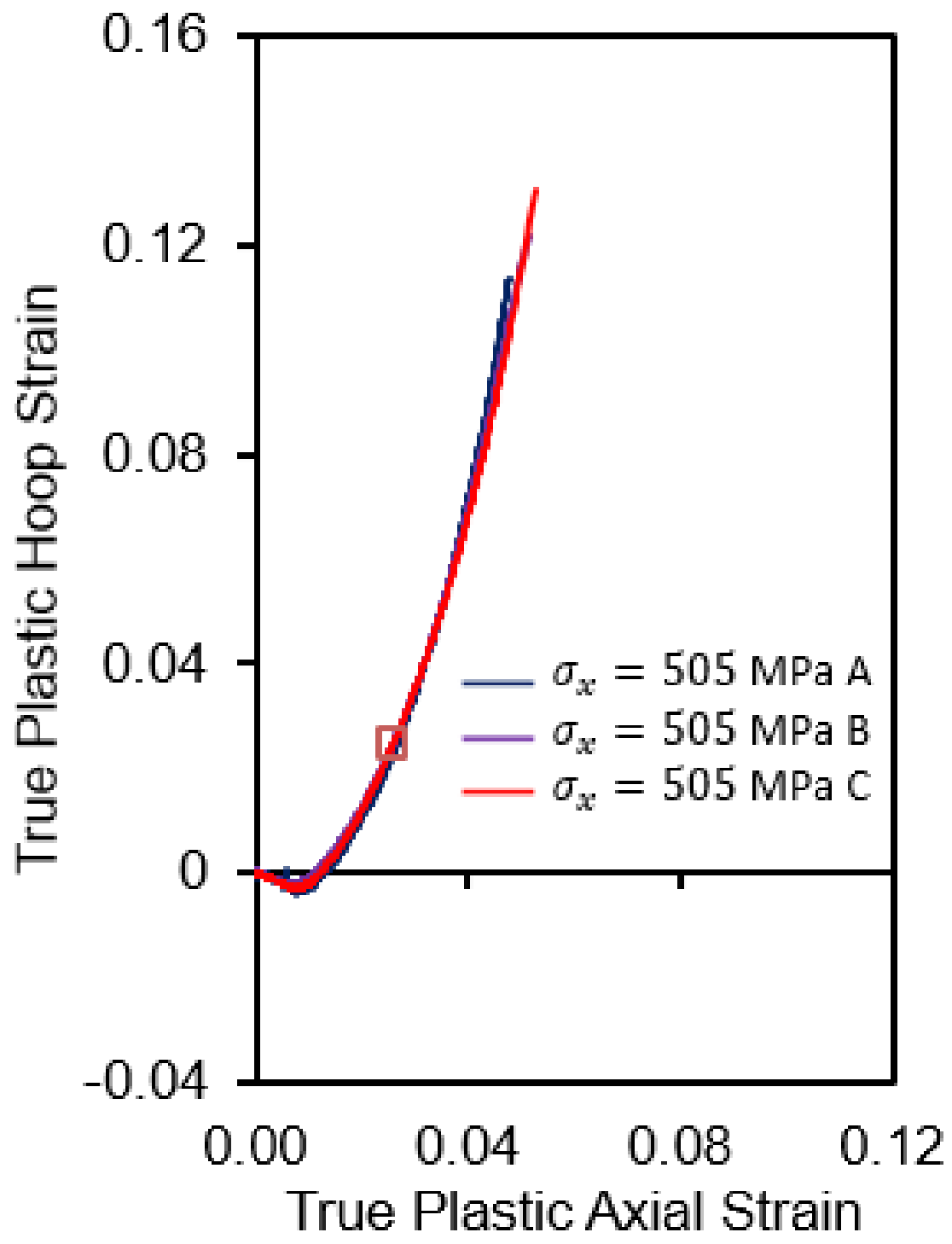

Figure 1.8: Repeatability of axial to hoop experiment with $\sigma_{x}=505 \mathrm{MPa}$ transition true stress 


\section{CHAPTER 2}

\section{PLASTICITY MODELING}

Plasticity models coded in MATLAB for yield criterion and strain hardening were used to predict true strain paths based on user-input stress paths with single or multiple loading segments, i.e., proportional or corner paths. In the current study, the plasticity modeling is presented only as a validation between experiments and model predictions. Later, the model will be used to optimize deformation paths producing the most beneficial microstructure for strength purposes, e.g., martensite transformation, while keeping the same final strain state related to the geometry of the product, e.g., shape and thickness. See Appendix A for the MATLAB code used to perform these calculations.

\subsection{Anisotropic Yield Criterion}

As shown in the experiment (see Fig. 1.5), SS316L clearly presents anisotropic behavior in both flow stress and strain during plastic deformation, which creates the necessity of an anisotropic yield criterion for the plasticity modeling. For this study, one of the simple anisotropic yield criteria, i.e., Hill 48 [22], was adopted to depict the material anisotropy due to the small number of experiments required to calibrate the material parameters of the yield criterion. For a plane stress state, Hill 48 can be simplified as

$$
\phi=F\left(\sigma_{y y}\right)^{2}+G\left(\sigma_{x x}\right)^{2}+H\left(\sigma_{x x}-\sigma_{y y}\right)^{2}+2 N\left(\sigma_{x y}\right)^{2}=\bar{\sigma}^{2}
$$

where $\mathrm{F}, \mathrm{G}$, and $\mathrm{H}$ are material parameters determined by plastic anisotropy. If $F=G=$

$H=\frac{N}{3}=\frac{1}{2}$, the equation reduces to von Mises isotropic yield criterion for plane stress. The 
subscripts $\mathrm{x}, \mathrm{y}$, and $\mathrm{z}$ represent three material orientations in general, thus, for the microtube specimens used in the study, they are assumed to be axial $(x)$, hoop $(\theta)$, and thickness $(t)$ directions. For the special case of zero shear stress, i.e., $\sigma_{x y}=0$, Eq. (2.1) reduces to:

$$
\phi=(G+H) \sigma_{x}^{2}+(F+H) \sigma_{\theta}^{2}-2 H \sigma_{x} \sigma_{\theta}=\bar{\sigma}^{2}
$$

The material parameters, i.e., F, G, and H, can be identified based on either stress or strain ratios, e.g., normalized stresses or r-values from uniaxial tension of sheets. In this study, only the approach based on strain ratios was considered, and the parameters were obtained as:

$$
\begin{gathered}
F=\frac{r_{x}}{r_{\theta}\left(1+r_{x}\right)} \\
G=\frac{1}{1+r_{x}} \\
H=\frac{r_{x}}{1+r_{x}}
\end{gathered}
$$

Here, the two strain ratios, $r_{x}$ and $r_{\theta}$, were calculated from the pure axial tension and pure hoop experiments, respectively. The identified parameters are summarized in Table 2. The yield locus predicted by Hill 48 in the $\sigma_{x}-\sigma_{\theta}$ plane is presented in Fig. 2.1, along with the von Mises isotropic yield locus for comparison. Experiments of normalized flow stresses from axial tension, pure hoop, and proportional biaxial tension experiments are also plotted together with both yield loci. Note that the flow stresses are overpredicted for pure hoop and proportional biaxial tension cases. This indicates potential concerns with being able to accurately predict stress and strain paths well by both yield criteria at those stress states.

\begin{tabular}{|c|c|c|}
\hline $\mathrm{F}$ & $\mathrm{G}$ & $\mathrm{H}$ \\
\hline 0.572 & 0.524 & 0.476 \\
\hline
\end{tabular}

Table 2.1: Anisotropic material parameters for Hill 48 yield criterion 


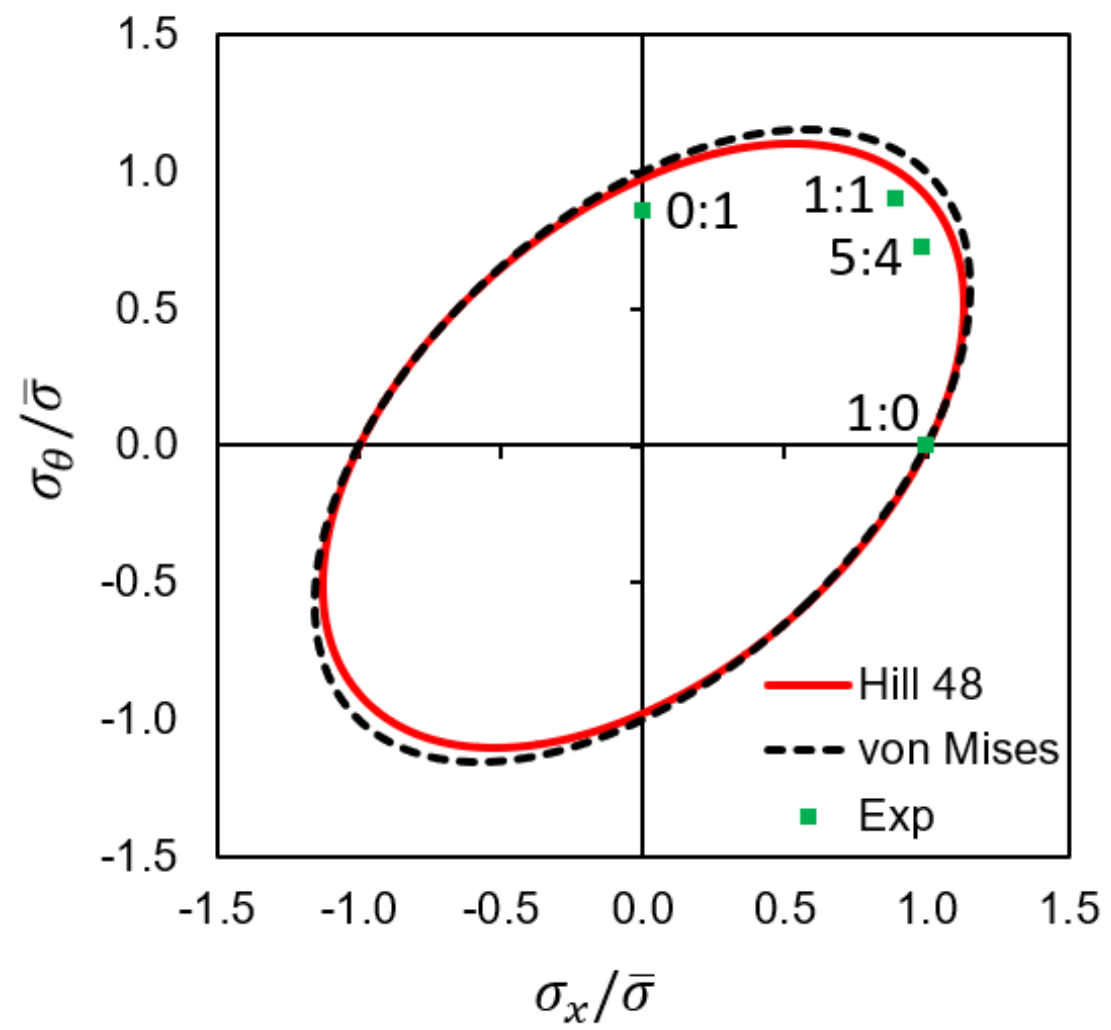

Figure 2.1: Yield loci of Hill 48 anisotropic yield criterion calibrated based on strain ratios and von Mises isotropic yield criterion

\subsection{Strain Hardening Law}

With the Hill 48 anisotropic yield criterion, the strain hardening behavior assuming isotropy is modeled using Hockett-Sherby hardening law:

$$
\bar{\sigma}=\sigma_{0}-\left(\sigma_{0}-A\right) \cdot \exp (-N \bar{\epsilon})^{p}
$$

where $\sigma_{0}$ is yield stress, $\bar{\sigma}$ is equivalent stress, and $\bar{\epsilon}$ is equivalent strain. The parameters of the equation, i.e., $A, N$, and $p$, are calibrated using the uniaxial tension stress-strain curve in the uniform deformation region, i.e., up to $\epsilon=0.25$. The calibrated result is shown in Fig. 1.8, and the parameters are summarized in Table 2.2. 


\begin{tabular}{|c|c|c|c|}
\hline$\sigma_{0}[\mathrm{MPa}]$ & $A[\mathrm{MPa}]$ & $N$ & $p$ \\
\hline 463.00 & 1828.10 & 1.73 & 0.85 \\
\hline
\end{tabular}

Table 2.2: Strain hardening parameters of Hockett-Sherby law

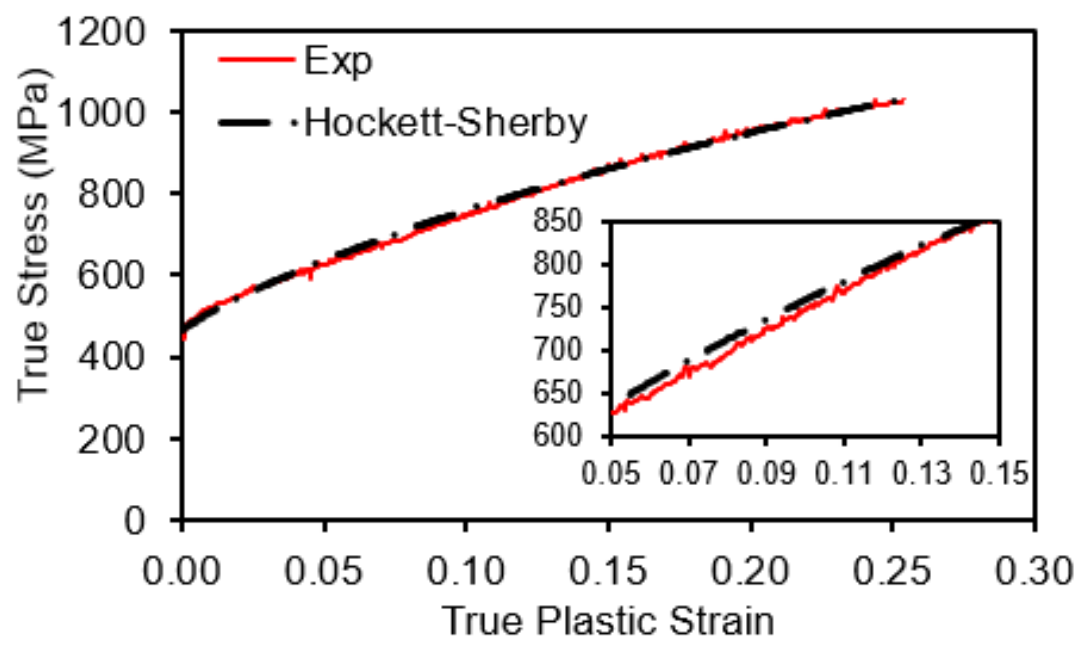

Figure 2.2: Hockett-Sherby law fitted to SS16L uniaxial experimental data

\subsection{Model Implementation}

The model is capable of predicting deformation paths for the three loading types described in this work: proportional, axial to hoop corner, and hoop to axial corner paths. Figure 2.3 presents a flow chart to calculate the true strain paths from the user-defined true stress paths. The code was programmed in MATLAB incorporating an isotropic strain hardening law, i.e., Hockett-Sherby, and an anisotropic yield criterion, i.e., Hill 48, for the material plasticity. Inputs for the calculations include material parameters for the plasticity models, transition stress and stress increments for the axial and the hoop directions to define the stress path, and the final strain state for the terminating condition. Stress and strain states are initialized to zero prior to entering the first loop to determine the plastic strain increment.

For the corner paths, i.e., axial to hoop and hoop to axial, a for loop is implemented for the first, user-defined stress path, i.e., pure axial or pure hoop. Within the for loop, the effective stress and strain are calculated based on the yield criterion and hardening law 


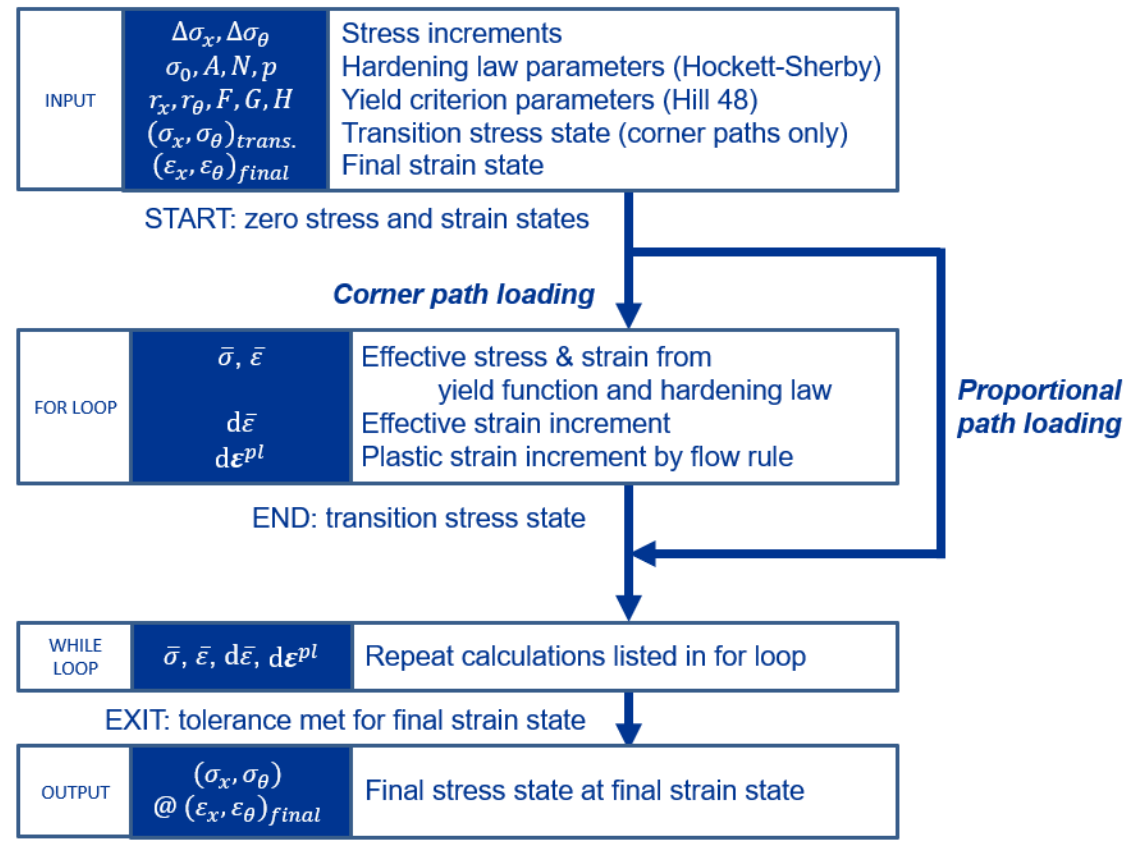

Figure 2.3: Flow diagram of model to predict strain paths from stress paths

following the stress path, and the plastic strain increment is calculated by the associated flow rule. The strain state is updated accordingly, and this iterative process continues until the specified transition stress state is reached.

For proportional paths, the for loop is bypassed, and the code directly enters the while loop. For the corner paths, the while loop is used to continue the calculations, from the for loop, for the second path segment. The calculation is terminated once a tolerance, defined by the minimum difference of the strain state at the end of the iteration against the desired final strain state, is satisfied. A break statement is imposed should the desired final strain state not be achieved with the given stress path.

\subsection{Model Validation}

Figure 2.4 shows a comparison of the predicted corner strain path for a single test, i.e., axial to hoop with $\sigma_{0}=635 \mathrm{MPa}$ transition true stress, using von Mises versus Hill 48 yield criterion in the model with the experimental result. The Hill 48 prediction more accurately captures the corner strain value and the curvature of both the axial and hoop loading segments due 
to the consideration of anisotropy with the strain ratios. Therefore, only Hill 48 is presented for all subsequent predictions.

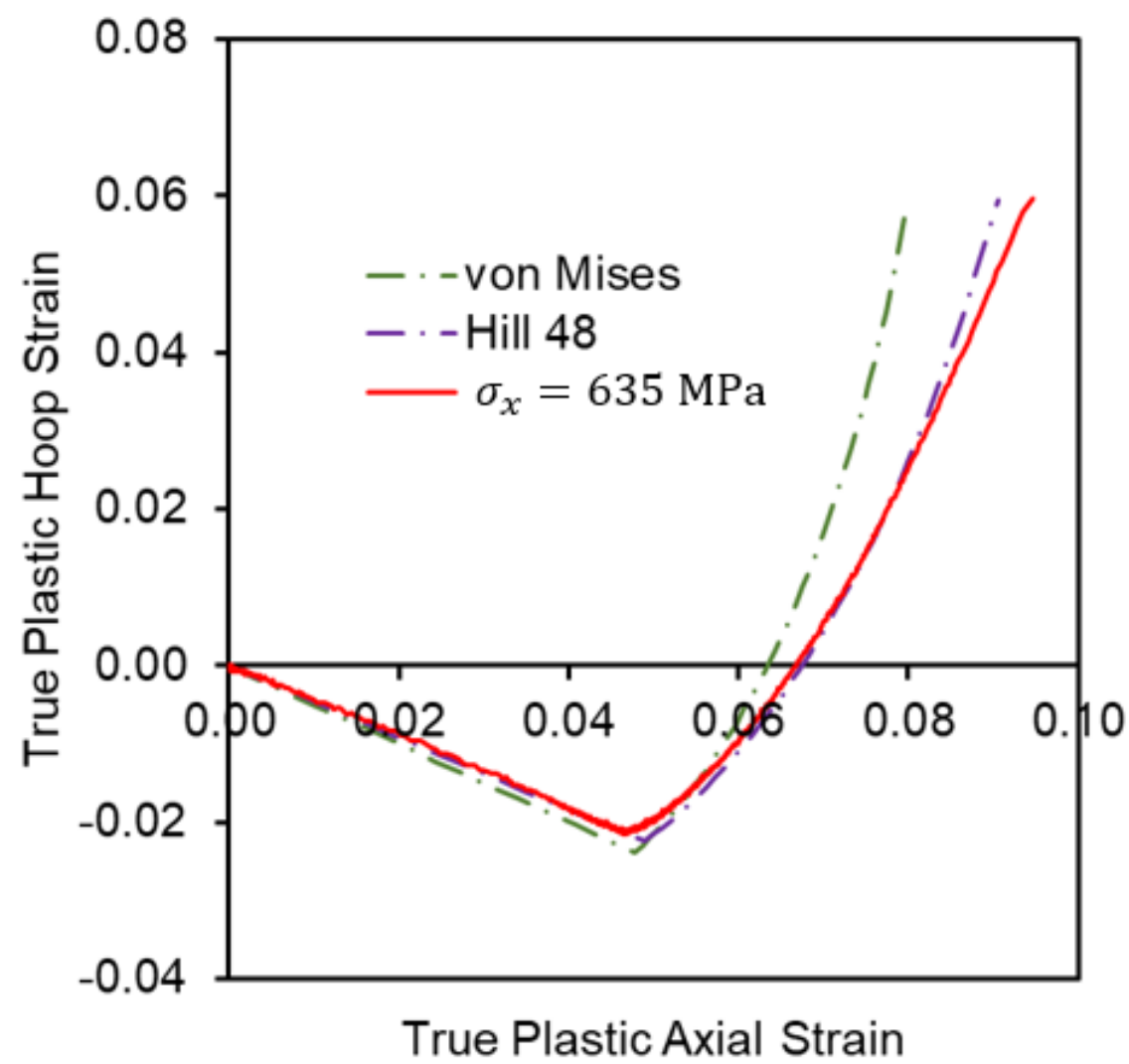

Figure 2.4: Comparison of von Mises and Hill 48 strain path predictions with experimental data

To validate the model, the same corner and proportional paths as the experiments, i.e., the same axial to hoop transition stresses for corner paths and the same stress ratios for the proportional paths, were input into the model. The three axial to hoop transition true stresses were $\left(\sigma_{x}: \sigma_{\theta}\right)=(505,0),(635,0)$, and $(785,0) \mathrm{MPa}$ which correspond to engineering stress values, i.e., machine inputs, of approximately $(500,0),(600,0)$, and $(700,0) \mathrm{MPa}$, respectively. The true stress and true strain path predictions are shown in Figs. 2.5a and 2.5b, respectively, with the experimental results for comparison. The path pairs targeting the same final strain state are color-coordinated, i.e., red, purple, and blue, for clarity, and markers are used to designate the final stress or strain state for each path pair. 


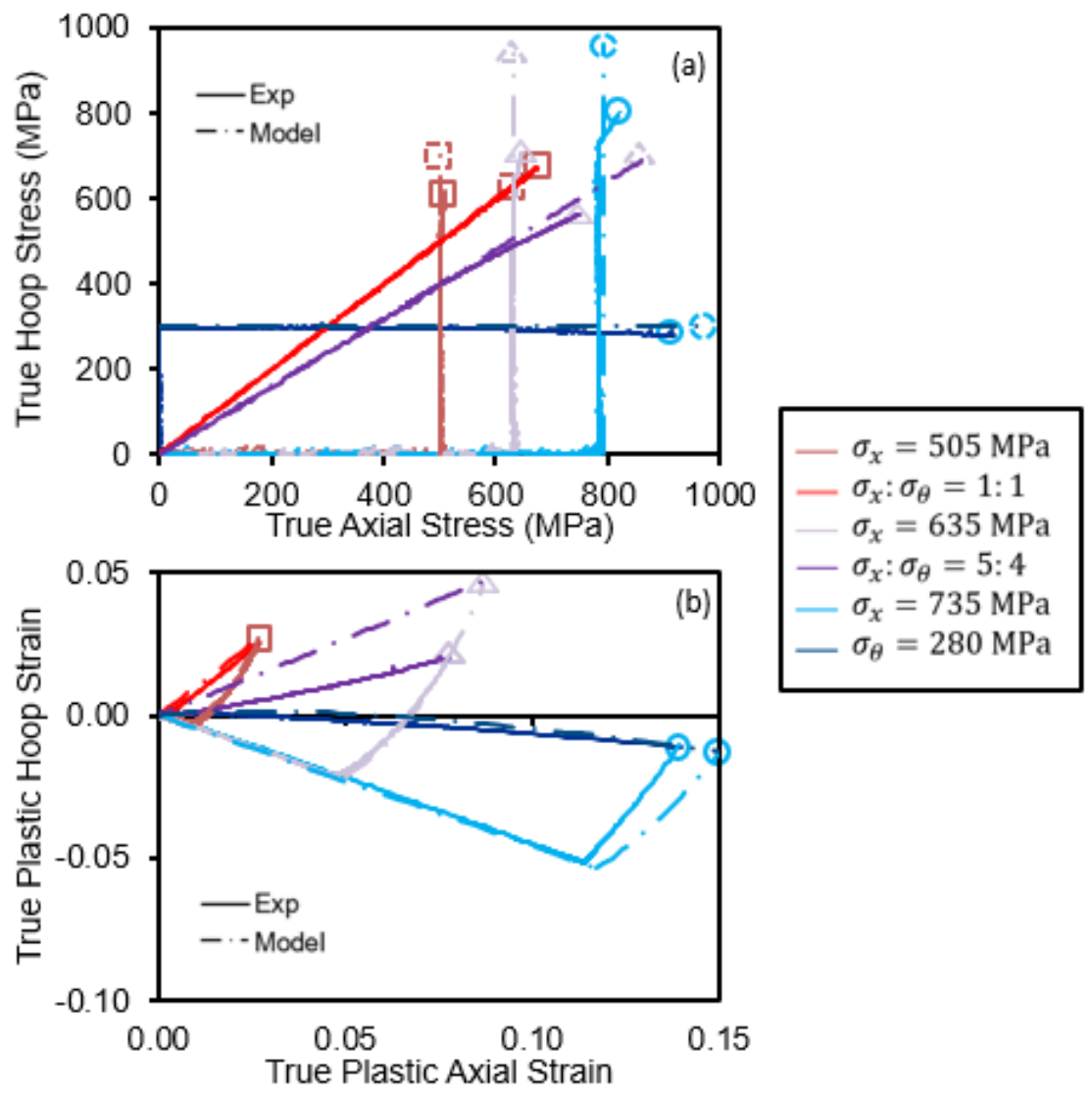

Figure 2.5: Comparison of predicted, i.e., model, and experimental true a) stress and b) strain for SS316L deformation paths

\subsection{Discussion}

As is evident in the experimental results, the model also predicts that multiple deformation paths achieving the same final strain state will result in differing final stress states. For the three axial to hoop corner paths shown in Fig. 2.5, the model is able to accurately predict the corner strain state with the closest to the experimental results being the $\sigma_{x}=505 \mathrm{MPa}$ transition true stress case (red in Fig. 2.5). For the axial to hoop corner paths, the model for the $\sigma_{x}=785 \mathrm{MPa}$ transition true stress case (light blue in Fig. 2.5) overpredicts the final true hoop stress up to approximately $220 \mathrm{MPa}$. This overprediction corresponds to the overprediction in flow stress by Hill 48 during biaxial loading (see Fig. 2.1). It also highly affects the strain paths as the tangent of the yield locus is associated with the incremental 
strain ratio for continued plastic deformation. As a result, some of the strain paths near the biaxial stress state show erroneous predictions. For example, the model prediction of the strain path for the 5:4 proportional loading case shows a comparatively higher slope than the experiment. This can be attributed to the higher slope along the normal direction of the yield locus predicted by Hill 48, i.e., $\frac{\epsilon_{\theta}}{\epsilon_{x}}$, near the 5:4 proportional loading case as seen in Fig. 2.1. This would create significant sensitivity to the strain paths if the yield criterion is not accurately represented in the model. Finally, as shown in Fig. 2.2, Hockett-Sherby predicts the overall strain hardening behavior well but does not capture the slight curvature variations visible (see insert) in the experimental data near the axial strain values from the corner paths, i.e., $0.05-0.1$. This would cause a slightly over or underpredicted flow stress depending on the range, which results in slight under or overestimated strain respectively in the plasticity model. Note that the stress paths for the hoop loading segments deviate from vertical near their ends for all axial to hoop corner paths due to the localization of the deformation, with this being most pronounced in the corner path case with the $\sigma_{x}=785$ MPa transition true stress case. The engineering to true stress-strain conversion is only valid during uniform deformation, which causes concerns for the ends of these curves.

Overall, the model predictions show reasonable agreement with the experimental results, but limitations of the current model are considered to account for the error in stress and strain path predictions (see Fig. 2.5). Future work will include modifying the model to account for these variations and improving the stress and strain predictions with an advanced anisotropic yield criterion, e.g., Yld2000-2D [23]. 


\section{CHAPTER 3 CONCLUSIONS}

Experimental results and plasticity models for SS316L microtubes subjected to various combinations of deformation, i.e., proportional and corner paths, to achieve the same final strain state are presented. The plasticity model prediction shows better agreement with the experimental results for linear and axial to hoop corner paths when utilizing the Hill 48 yield criterion compared to von Mises, as material anisotropy is captured. When predicting the

final true stress state for axial to hoop corner paths with large (> $500 \mathrm{MPa})$ axial stress values, the model overpredicts the final hoop stress, and the corresponding strain paths deviate from the experimental results. However, these results are deemed reasonable considering the complicated biaxial deformation of the microtube inflated under axial force and internal pressure. Hoop to axial corner paths show significant specimen to specimen variation and even discrepancies based on axial location for a given specimen due to grain size effects. These differing strain paths for a specific loading case demonstrate the need to account for such process size effect considerations during microforming. 


\section{CHAPTER 4 FUTURE WORK}

Future work will include simulating the microtube inflation/tension proportional and corner paths in a finite element software that will be validated by experimental results. Additionally, this austenitic stainless steel exhibits martensitic phase transformations that alter the microstructure and are of interest for creating heterogeneous biomaterials. Thus, samples will be removed from the deformed microtubes and subjected to electron backscatter diffraction (EBSD) to characterize the resulting phase fractions. As mentioned in Chapter 2, the models will also be modified to improve the stress and strain predictions using an advanced anisotropic yield criterion. 


\section{LIST OF REFERENCES}

[1] Qin, Yi (2015) Chapter 1 - Overview of Micro-manufacturing, In Micro and Nano Technologies, Micromanufacturing Engineering and Technology (2nd Edition), William Andrew Publishing, pp. 1-33, ISBN 9780323311496, https://doi.org/10.1016/B978-0-323-31149-6.000013.

[2] Beltran, M., Malhotra, R., Nelson, A. J., Bhattacharya, A., Reddy, N. V., and Cao, J. (2013) Experimental study of failure modes and scaling effects in micro-incremental forming." ASME. Journal of Micro and Nano-Manufacturing. 1(3): 031005. https://doiorg.unh.idm.oclc.org/10.1115/1.4025098

[3] Jiang, C.-P., \& Chen, C.-C. (2012) Grain size effect on the springback behavior of the microtube in the press bending process. Materials \& Manufacturing Processes, 27(5), 512-518. https://doi-org.unh.idm.oclc.org/10.1080/10426914.2011.593230

[4] Lai, X., Peng, L., Hua, P., Lan, S., and Ni, J. (2008) Material behavior modelling in micro/meso-scale forming process with considering size/scale effects. Computational Materials Science, 43, 1003-1009.

[5] Peng, L., Liu, F., Ni, J., and Lai, X. (2007) Size effects in thin sheet metal forming and its elastic plastic constitutive model. Materials and Design, 28, 1731-1736. 
[6] Peng, L., Hu, P., Lai, X., Mei, D., and Ni, J. (2009) Investigation of micro/meso sheet soft punch stamping process simulation and experiments. Materials and Design, 30, 783-790.

[7] Razali, Akhtar Razul, Qin, Yi (2013) A Review on Micro-manufacturing, Micro-forming and their Key Issues. Procedia Engineering, Vol. 53, 2013, pp. 665-672, ISSN 1877-7058, https://doi.org/10.1016/j.proeng.2013.02.086.

[8] Zheng, J., and Fu, M. (2020) Progressive and compound forming for producing plungertyped microparts by using sheet metal. ASME. Journal of Micro Nano-Manufacturing. 8(2): 024508. https://doi.org/10.1115/1.4046281

[9] Ehmann, K. F., Bourell, D., Culpepper, M. L., Hodgson, T. J., Kurfess, T. R., Madou, M., ... \& DeVor, R. E. (2005) International assessment of research and development in micromanufacturing. World Technology Evaluation Center Inc., Baltimore, MD.

[10] Becker, C., Tekkaya, A.E., Kleiner, M. (2014) Fundamentals of the incremental tube forming process. CIRP Annals. 63, 253-256.

https://doi.org/https://doi.org/10.1016/j.cirp.2014.03.009

[11] Meya, R., Löbbe, C., Tekkaya, A.E. (2019) Stress state analysis of radial stress superposed bending. International Journal of Precision Engineering and Manufacturing. 20, 53-66. https://doi.org/10.1007/s12541-019-00040-0

[12] Ripley, P.W. and Korkolis, Y.P. (2016) Multiaxial Deformation Apparatus for Testing of Microtubes Under Combined Axial-Force and Internal-Pressure. Experimental Mechanics 56: 273. https://doi.org/10/1007/s11340-015-0097-y. 
[13] Ripley, PW (2014) Biaxial stress testing of SS-304L microtubes by axial load and internal pressure. MS Thesis, Univ. New Hampshire.

[14] Knysh, Paul and Korkolis, Yannis P. (2017) Identification of the post-necking hardening response of rate- and temperature-dependent metals. International Journal of Solids and Structures, Vol. 115-116, pp. 149-160, ISSN 0020-7683, https://doi.org/10.1016/j.ijsolstr.2017.03.012.

[15] Korkolis, Y.P. and Kyriakides, S. (2008) Inflation and burst of anisotropic aluminum tubes for hydroforming applications. International Journal of Plasticity, 24/3, 509-543.

[16] Korkolis, Y.P. and Kyriakides, S. (2008) Inflation and burst of anisotropic aluminum tubes, part II: an advanced yield function including deformation-induced anisotropy. International Journal of Plasticity, 24/9, 1625-1637.

[17] Korkolis, Y.P. and Kyriakides, S. (2009) Path-dependent failure of inflated aluminum tubes. International Journal of Plasticity, 25/11, 2059-2080.

[18] Korkolis, Y.P., Kyriakides, S., Giagmouris, T., Lee, L.-H. (2010) Constitutive modeling of rupture predictions of Al-6061-T6 tubes under biaxial loading paths. Journal of Applied Mechanics - ASME, 064501-1/-5.

[19] Cullen, G. and Korkolis, Y.P. (2013) Ductility of 304 stainless steel under pulsed uniaxial loading. International Journal of Solids and Structures, 50, 1621-1633.

[20] Knysh, P., and Korkolis, Y.P. (2015) Determination of the fraction of plastic work converted into heat in metals. Mechanics of Materials, 86, 71-80. 
[21] TE Connectivity: MicroGroup, Inc. (2019) SS316L Certification of Compliance/Material.

[22] Hill, R. (1948) A theory of the yielding and plastic flow of anisotropic metals. Proc. R. Soc. London A Math. Phys. Eng. Sci. 193, 281-297.

[23] Barlat, F., Brem, J.C., Yoon, J.W., Chung, K., Dick, R., Lege, D.J., Pourboghrat, F., Choi, S., \& Chu, E. (2002) Plane stress yield function for aluminum alloy sheets - part 1: theory. International Journal of Plasticity, 19, 1297-1319. 
APPENDIX A

SUPPLEMENTAL FIGURES

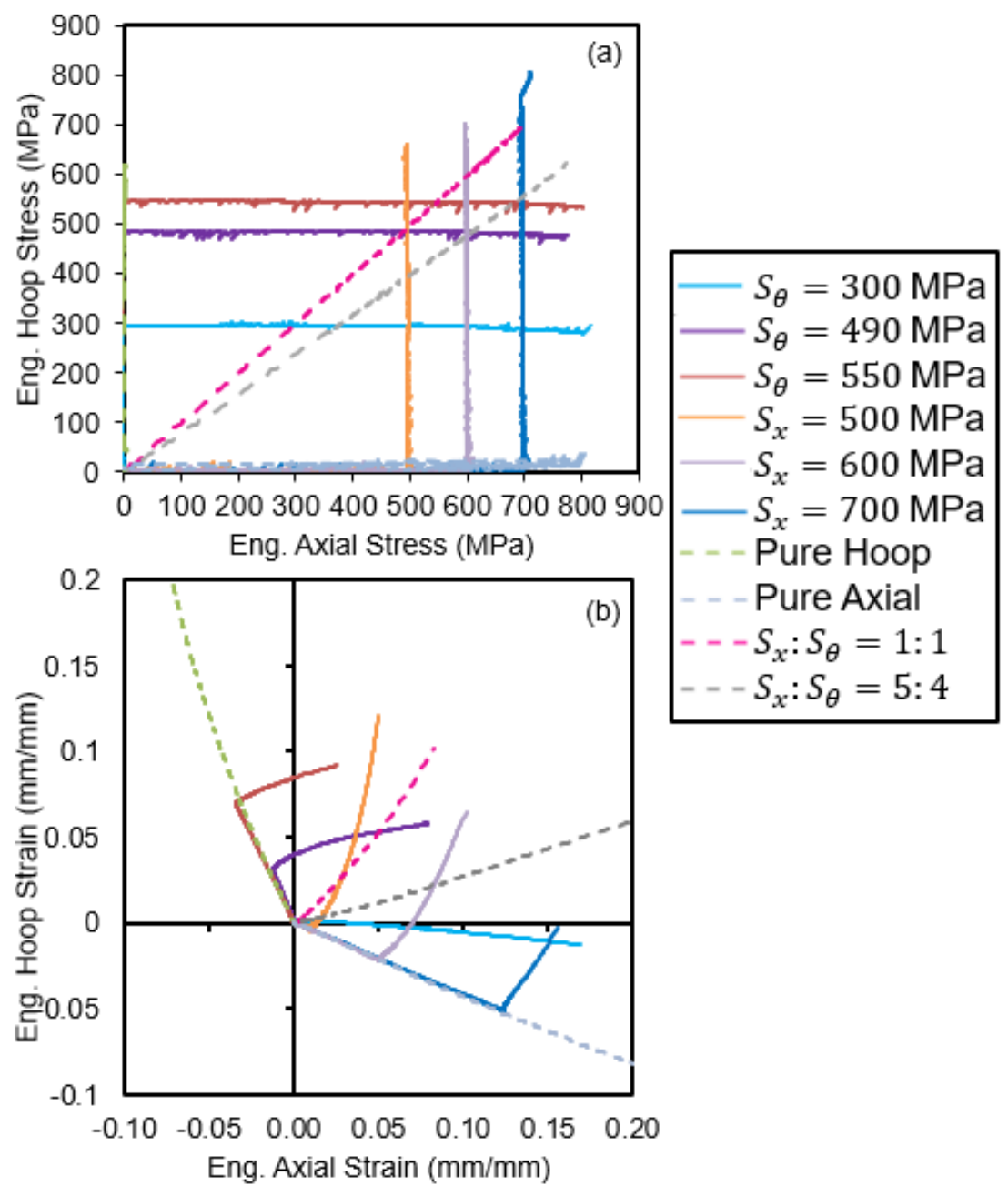

Figure A.1: Engineering a) stress and b) strain paths from corner (solid) and proportional (dashed) loading path experiments 


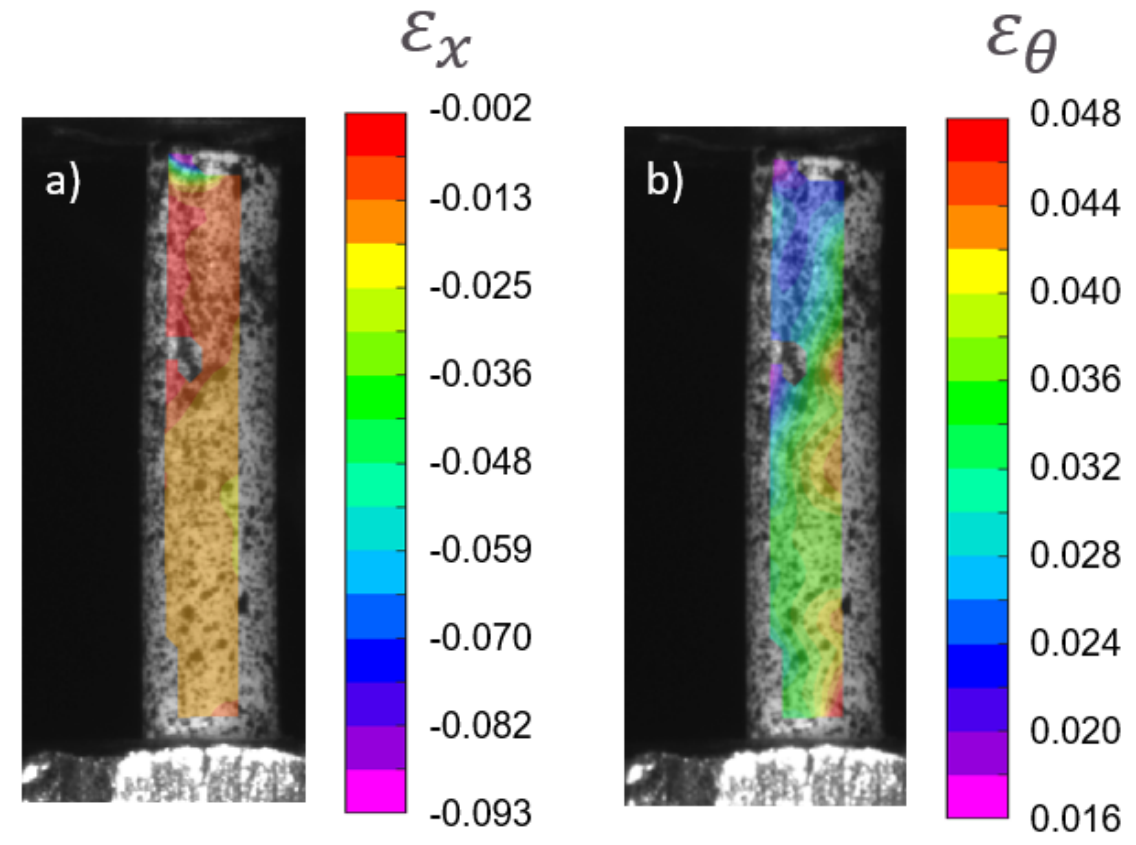

Figure A.2: Experimental 3D DIC true a) axial and b) hoop strains from a hoop to axial corner loading test just prior to failure 


\section{APPENDIX B}

\section{MATLAB CODE}

This section contains the MATLAB code for the plasticity model described in chapter 3. A hoop to axial corner path input was implemented as an example.

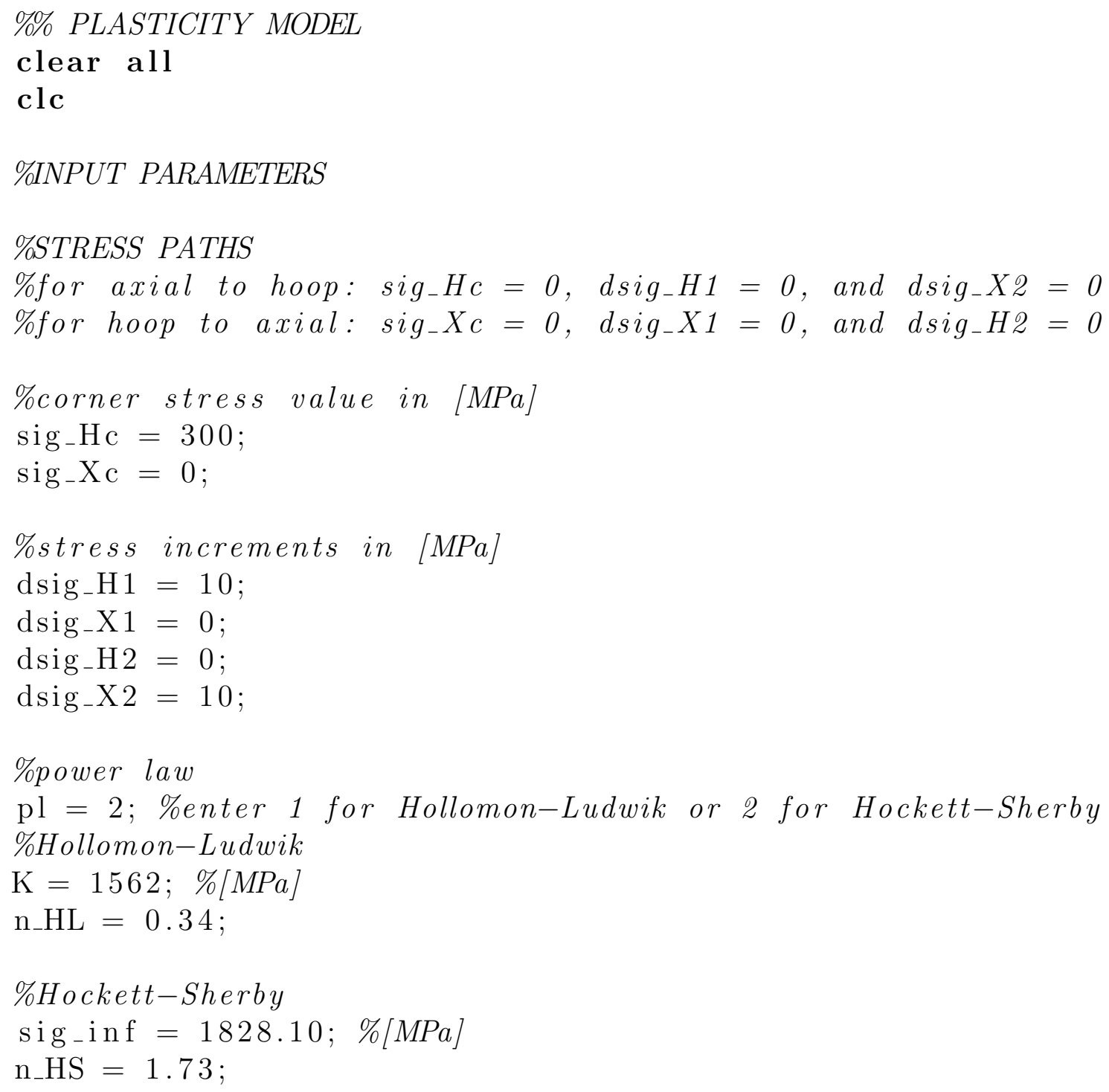




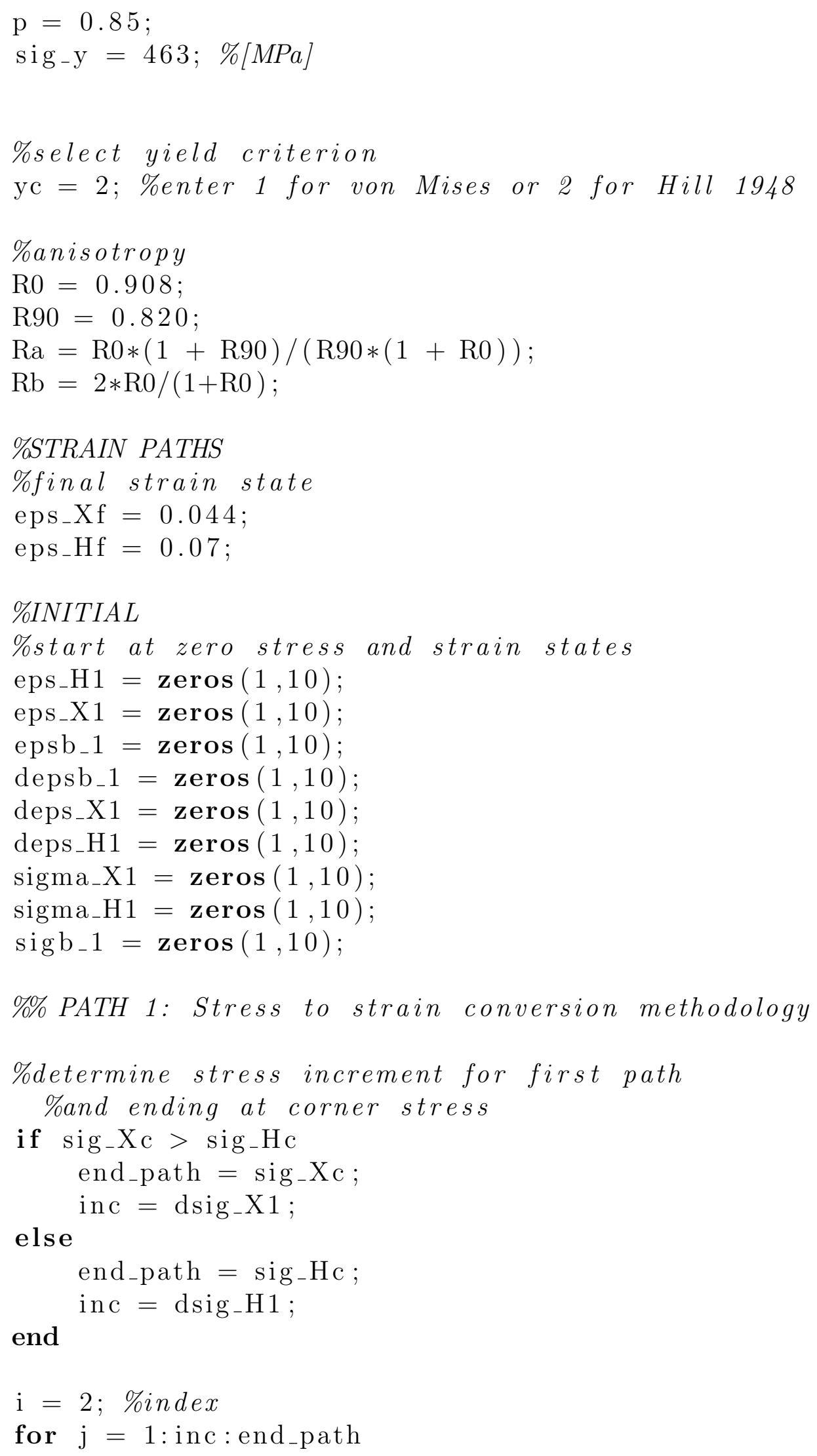




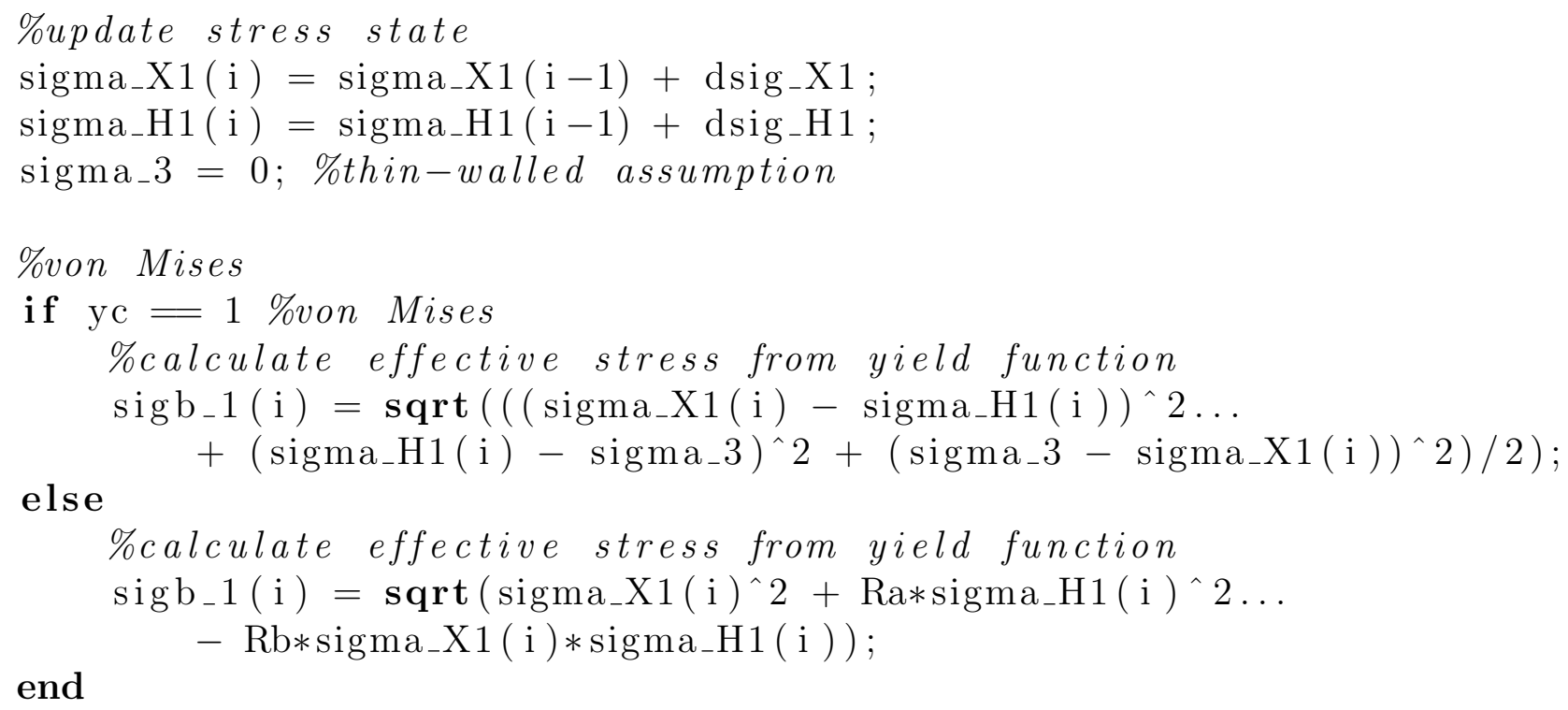

\%calculate change in effective strain depsb_1 (i) = epsb_1(i) - epsb_1(i - 1);

if $\mathrm{yc}=1$

\%calculate plastic strain increment from associated flow rule $\operatorname{deps}_{-} \mathrm{X} 1(\mathrm{i})=\mathrm{deps}_{-} 1(\mathrm{i}) *(\operatorname{sigma} \mathrm{X} 1(\mathrm{i}) \ldots$ $\left.-\left(\operatorname{sigma\_ H1}(\mathrm{i})+\operatorname{sigma\_ }_{-}\right) / 2\right) / \operatorname{sigb\_ 1}(\mathrm{i})$;

deps_H1 (i $)=$ depsb_1 $_{-}(\mathrm{i}) *\left(\operatorname{sigma\_ H1}(\mathrm{i}) \ldots\right.$

else$$
\left.-\left(\operatorname{sigma\_ } 3+\operatorname{sigma\_ X1}_{-}(\mathrm{i})\right) / 2\right) / \operatorname{sigb\_ } 1(\mathrm{i}) \text {; }
$$

\%calculate plastic strain increment from associated flow rule $\operatorname{deps}_{-} \mathrm{X} 1(\mathrm{i})=\mathrm{depsb}_{-} 1(\mathrm{i}) *\left(\left(2 * \mathrm{Ra}_{*} \operatorname{sigma\_ X} 1(\mathrm{i}) \ldots\right.\right.$

$-\mathrm{Rb} * \operatorname{sigma} H 1(\mathrm{i})) / 2) / \operatorname{sigb} 1$ (i ) ;

$\operatorname{deps}_{-} H 1(\mathrm{i})=\mathrm{depsb}_{-} 1(\mathrm{i}) *\left(\left(2 * \mathrm{Ra}_{*} \operatorname{sigma\_ H1}(\mathrm{i}) \ldots\right.\right.$ 


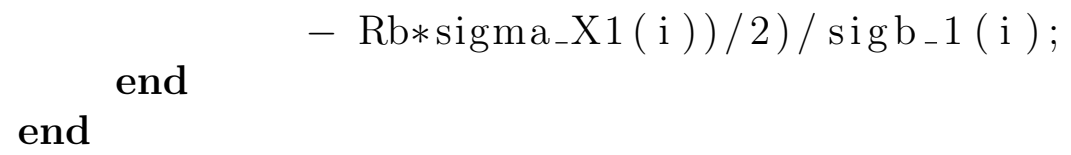




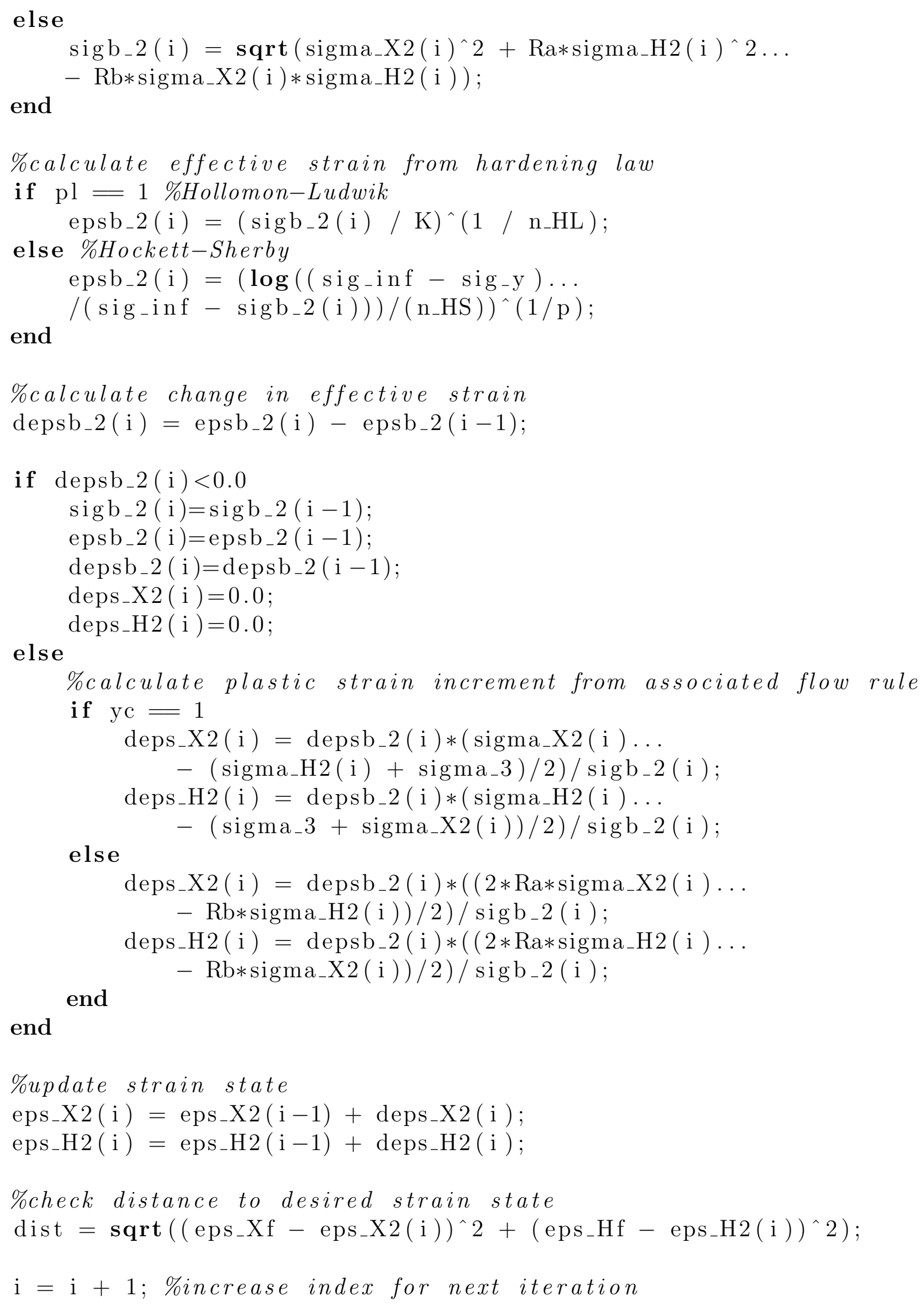


\%if strain path will not intersect desired final strain state \%then corner stress state needs adjusted

if dist $>0.2$

break

end

end

$\%$ plots

\%properties

set (gca,' 'linewidth', 1.5) \%axes line thickness

set (findall (gcf, '-property', 'FontSize'), 'FontSize',22) \%font size

$\%$ PATHS 1832

plot ( sigma_X1, sigma_H1, sigma_X2, sigma_H2 );

\%plot (sigma_X1, sigma_H1);

xlabel ('True Axial $_{-}$Stress $(\mathrm{MPa})$ ') ;

ylabel ('True $H_{H o o p} \mathrm{Stress}_{\llcorner}(\mathrm{MPa})$ ') ;

figure (2)

$\operatorname{plot}\left(\operatorname{eps}{ }_{-} \mathrm{X} 1\right.$, eps_H1, eps_X 2 , eps_H2 $)$;

$\%$ plot (eps_X1, eps_H1);

xlabel ('True $\left.A x i a l \_S t r a i n '\right)$;

ylabel ('True Hoop $_{\llcorner}$Strain');

$x \lim \left(\left[\begin{array}{ll}-0.1 & 0.25\end{array}\right]\right)$

$y \lim \left(\left[\begin{array}{ll}-0.1 & 0.25\end{array}\right]\right)$

\%legend('von Mises', 'von Mises', 'Hill 48', 'Hill 48');

if $\mathrm{yc}=1$

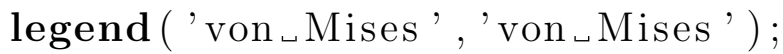

else

end

legend ('Hill_48', ' Hill_48'); 